\title{
Heat-Related Symptoms in Sugarcane Harvesters
}

\author{
Jennifer Crowe, MPH, PhD, ${ }^{1 *}$ Maria Nilsson, $\mathrm{PhD}^{2}{ }^{2}$ Tord Kjellstrom, MD, PhD, ${ }^{2,3}$ \\ and Catharina Wesseling, $\mathrm{MD}, \mathrm{PhD}^{4}$
}

\begin{abstract}
Background Exposure to heat stress is a documented risk for Central American sugarcane harvesters. However, little is known about heat-related illness in this population.

Methods This study examined the frequency of heat-related health effects among harvesters $(n=106)$ exposed to occupational heat stress compared to non-harvesters $(n=63)$. Chi-square test and gamma statistic were used to evaluate differences in selfreported symptoms and trends over heat exposure categories.

Results Heat and dehydration symptoms (headache, tachycardia, muscle cramps, fever, nausea, difficulty breathing, dizziness, swelling of hands/feet, and dysuria) were experienced at least once per week significantly more frequently among harvesters. Percentages of workers reporting heat and dehydration symptoms increased in accordance with increasing heat exposure categories.

Conclusions A large percentage of harvesters are experiencing heat illness throughout the harvest demonstrating an urgent need for improved workplace practices, particularly in light of climate change and the epidemic of chronic kidney disease prevalent in this population. Am. J. Ind. Med. 58:541-548, 2015. (c) 2015 Wiley Periodicals, Inc.
\end{abstract}

KEY WORDS: agricultural worker; sugarcane; heat stress; Central America; chronic kidney disease; climate change

\section{INTRODUCTION}

Occupational heat stress is an important potential consequence of climate change [Kjellstrom, 2009; Kjellstrom et al., 2013a,b]. The negative effects of over-exposure to heat include diminished mental and physical health [Tawatsupa et al., 2010], diminished work capacity and increased injury risk [NIOSH, 1986; Ramsey, 1995; Hancock et al., 2007; Sahu et al., 2013]. Workplace heat exposure

${ }^{1}$ Regional Institute for Studies on Toxic Substances (IRET), Program on Health, Work and Environment (SALTRA), Universidad Nacional, Heredia, Costa Rica

${ }^{2}$ Umeå Centre for Global Health Research, Umeå University, Umeå, Sweden

${ }^{3}$ Environment International Trust, Mapua, NewZealand

${ }^{4}$ Institute of Environmental Medicine, Karolinska Institutet, Stockholm, Sweden

Contract grant sponsor: Umeå University and Australian National University; Contract grant sponsor: Fondo Institucional de DesarrolloAcadémico/Institutional Fund for Academic Development (FIDA) From Costa Rica's Universidad Nacional.

${ }^{*}$ Correspondence to: J. Crowe, MPH, PhD, IRET-UNA 86-3000 Heredia, Costa Rica.

E-mail:Jennifer.crowe@una.cr

Accepted 26 February 2015

DOI 10.1002/ajim.22450. Published online in Wiley Online Library (wileyonlinelibrary.com). is an important issue in multiple sectors and countries [Robins et al., 1998; Donoghue et al., 2000; Srivastava et al., 2000; McGeehin and Mirabelli, 2001; MMWR and CDC, 2008; Kjellstrom and Crowe, 2011; Pires Bitencourt et al., 2012; Fleischer et al., 2013; Nevarez, 2013; StoecklinMarois et al., 2013]. The effect of increasing heat on work capacity and labor productivity is expected to be the leading global economic impact of climate change in developing countries, with projected costs in Costa Rica of nine billion dollars in 2030 [DARA, 2012].

Heat exposure results from both climate conditions and internal heat created by muscle movement. Minor heat illnesses include edema, syncope (fainting as a result of blood pooling in the extremities) and cramps [Parsons, 2014], eventually leading to the more serious condition of heat exhaustion. Heat exhaustion results from cardiac failure to simultaneously meet the demands of thermoregulation and physical activity, but without notable organ damage. It often occurs in conjunction with dehydration, and manifests itself as a range of heat-related symptoms such as fatigue, headache, muscle cramps, weakness, dizziness, nausea, vomiting, tachycardia, hyperventilation, ataxia, 
malaise, hypotension, and transient alteration in mental status [Department of the Army and Air Force, 2003]. The most severe outcome of heat exposure is heat stroke, a medical emergency in which the body's core temperature remains above $40^{\circ} \mathrm{C}$, provoking multiple organ failure, neurological damage, convulsions, unconsciousness and, potentially, death [Department of the Army and Air Force, 2003].

Sugarcane is an important crop for Costa Rica, with an annual production value of approximately 100 million USD [FAOSTAT, 2014], and a continual increase in production and land dedicated to the crop [SEPSA, 2013]. Much harvesting is done by workers cutting cane manually. Most workers live in poverty and work in conditions that increase their vulnerability such as working for subcontractors and living in labor camps [Crowe et al., 2013].

Heat stress in sugarcane harvesters has been reported in Costa Rica and Nicaragua [Delgado Cortez, 2009; Crowe et al., 2013]. This has received particular attention for possible links to the devastating epidemic of chronic kidney disease (CKD) in Mesoamerican worker populations, notably sugarcane harvesters [Brooks et al., 2012; Wesseling et al., 2013; Correa-Rotter et al., 2014]. Heat exposure and working conditions for harvesters have been characterized previously [Crowe et al., 2013]. Heat stress exposure was measured using the Wet Bulb Globe Temperature (WBGT) index, and recommendations (NTP_-Notas Técnicas en Prevención) from the National Institute of Occupational Safety and Health in Spain were used to estimate metabolic load and the corresponding limit values for avoiding heat stress. It was found that sugarcane harvesters have a metabolic load of about $260 \mathrm{~W} / \mathrm{m}^{2}(6.8 \mathrm{kcal} / \mathrm{min})$, corresponding to a recommended limit value of $26^{\circ} \mathrm{C}$ WBGT, which was reached by 7:30 am on most days. Since the shift generally runs from about 5:30 am until noon, harvesters work most of their shift under conditions of heat stress. If the hourly average metabolic load is reduced by regular rest breaks or by slowing down work pace, higher heat levels are acceptable [Parsons, 2014]. Of particular note is that harvesters are paid according to how much they cut. Costa Rican national workplace regulations contain almost no protection measures from heat.

This study is part of a 3-year investigation on heat exposure and health effects in sugarcane harvesters in Costa Rica. Specifically, we aimed to determine the frequency of self-reported heat-related symptoms among harvesters exposed to heat stress as compared to non-harvesters working in the same company.

\section{MATERIALS AND METHODS}

\section{Participant Selection}

The heat-exposed participants were subcontracted sugarcane harvesters. We invited all 100 workers of subcontractor 1 and 20 of the workers from subcontractor 2 (i.e., all those who were present in the field at the time researchers were measuring WBGT). Of the 120 invited workers, 111 men participated (response 93\%), and 106 with complete data were used for analysis.

The non-heat exposed were "non-harvesters" working during daytime in offices, part of the processing plant, machinery shop, storage area, or cafeteria. Researchers entered the premises with permission from administrators and invited men present at the moment and, in addition, some other field workers with little-to-no heavy physical labor. All participants gave written consent to participate in the questionnaire. The study was approved by the Bioethics Board of Universidad Nacional.

\section{Data Collection}

Data collection took place in February 2011, approximately 2 months into the harvest. Harvesters were interviewed in the field after finishing their shift in the afternoon in the labor camp. Non-harvesters were interviewed at the moment they were contacted at their work stations.

A small pilot study was done in 2010 to test the understandability and feasibility of the symptom questionnaire with questions based on the US Military recommendations [Department of the Army and Air Force, 2003]. The final 64-item questionnaire included symptom questions (with local terms used for rhinorrhea, dysuria, and tachycardia), questions about demographics, current and previous work, housing, common work day, habits (diet, smoking and alcohol) and liquid consumption.

Symptoms were categorized into: heat-related symptoms, dehydration symptoms, symptoms known to be related to cane cutting, and symptoms not known to be related to cane cutting. Heat-related symptoms were headache, tachycardia, muscle cramps in the arms or legs, fever, nausea, difficulty breathing, swelling of hands or feet, dizziness, vomiting and fainting [Department of the Army and Air Force, 2003] and dehydration symptoms were dry mouth and dysuria [Ramirez-Rubio et al., 2013]. We also asked about non-heat related symptoms to improve the interpretation and credibility of the self-reported heat-related symptoms. Symptoms known to be related to sugarcane cutting consisted of ergonomic symptoms (pain in upper part of back and pain in lower part of back) related to awkward postures during long working hours [Vergüizas Valverde et al., 2007] and respiratory symptoms (rhinorrhea and sneezing) related to inhalation of dust and bagasse [Gascon et al., 2012]. Symptoms not known to be related to cane cutting were stomachache, diarrhea, difficulty buttoning shirt, nosebleed and earache.

For each symptom, the participant was asked whether he had experienced it at some point during the current harvest. If the answer was positive, he was asked whether he 
experienced the symptom "almost every day," "at least once a week," "at least once a month," "2-3 times during the current harvest," or "only once."

We hypothesized a priori, that heat and dehydrationrelated symptoms would occur more frequently among harvesters than among non-harvesters, as would other symptoms known to be related to cane cutting; and that there would be no relevant differences between the groups with regard to symptoms not known to be related to cane cutting.

\section{Statistical Analysis}

Chi-square tests and Fisher's exact test (when expected values were less than five in any of the cells of the contingency tables) were used to determine whether significant differences existed between the symptoms reported at least once a week (including "almost every day") and symptoms reported less than once per week (including never) among harvesters versus non-harvesters. For trend analysis, job category was used as a proxy for heat exposure and gamma statistic was used to evaluate significance for trends in symptom reporting across increasing heat exposure by job categories.

\section{RESULTS}

Of the non-harvesters, $36 \%$ worked in offices with air conditioning, $29 \%$ in the machine shop or storage sheds of the processing plant, $22 \%$ as field-based supervisors (including one driver), and 13\% in various ("other") jobs (Table I). All $(n=63)$ agreed to participate when approached, but no effort was made to gain the participation of workers who were away from their workstation.

Harvesters were slightly younger than non-harvesters and reported slightly more smoking ( $25 \%$ vs. $18 \%$ ), whereas non-harvesters more often reported consuming alcohol (76\% vs. $45 \%$ ) and had, as expected, considerably more education (median 12 vs. 5 years). The majority ( $82 \%$ ) of harvesters lived in a labor camp during the 5-month harvest season, while $18 \%$ lived in their own homes (Table I). All those living in the labor camp were migrants from Nicaragua. All non-harvesters had housing near or inside the company's property.

Table II shows the symptoms and frequencies reported by harvesters and non-harvesters. All heat and dehydrationrelated symptoms experienced at least once per week were significantly different between harvesters and non-harvesters $(P<0.05)$ with the exception of vomiting and dry mouth. Fainting was experienced once since the start of the season by three harvesters versus no non-harvesters $(P=0.29)$. All four symptoms related to harvesting but not to heat (pain in the upper back, pain in the lower back, sneezing, and rhinorrhea) were reported significantly more frequently at least once a week by harvesters than non-harvesters, although all symptoms except rhinorrhea were also relatively common in non-harvesters. None of the non-heat related symptoms were different between the groups in the "at least once a week" category.

The most common symptom reported for all job titles was headache, but it was significantly higher in harvesters, $51 \%$ at least once a week (including $20 \%$ almost every day) versus $25 \%$ at least once a week (including $3 \%$ almost every day; $P=0.001$ ) among non-harvesters. The next most common symptoms reported at least once a week were: tachycardia (35\% vs. $5 \% ; P<0.001)$, dry mouth $(32 \%$ vs. $22 \%, P=0.189)$, and dysuria $(28 \%$ vs. $3 \% ; P<0.001)$. Of the 38 harvesters that reported dysuria, $79 \%$ had the symptom at least once per week.

The number of heat-related symptoms at least once a week reported by each individual was higher for harvesters than non-harvesters, $82 \%$ of harvesters compared to $49 \%$ of non-harvesters reported $\geq 1$ symptoms; for $\geq 2$ symptoms, these figure were $59 \%$ versus $19 \%$ and for $\geq 3$ symptoms $42 \%$ versus $3 \%$.

When analyzing by the heat sub-categories: (office and various workers with no heat exposure, field and plant workers with intermediate heat exposure and harvesters with high heat exposure), a clear trend was seen for the majority of heat and dehydration-related symptoms (Fig. 1) with the percentage of workers reporting heat and dehydration symptoms increasing as heat exposure increased. No significant trends were seen for symptoms not related to cane harvesting (data not shown).

\section{DISCUSSION}

This study shows clear differences in self-reported heat and dehydration-related symptoms between harvesters and non-harvesters and a trend of increasing symptoms with increasing heat exposure across job categories, consistent with the a priori hypotheses.

Since heat-related symptoms are not unique to heat exposure, it is likely that part of the reported symptoms were due to other factors. By focusing the analyses on the "at least once a week" category, we accounted for symptoms experienced infrequently as a result of non-heat related conditions. The only two symptoms in the "at least once a week" category not statistically different between harvesters and non-harvesters were vomiting and fainting - conditions that would make working very difficult if experienced weekly. Notably, three of the harvesters reported fainting during the harvest. Reporting of one, two and $\geq$ three symptoms at least once a week was respectively two, three and 14 times more frequent among the heat exposed harvesters. Additionally, the trend of increasing symptoms with increasing heat exposure across job categories provides 
TABLE I. Characteristics of the Study Population

\begin{tabular}{|c|c|c|}
\hline & Harvesters $(n=106)$ & Non-harvesters $(n=63)$ \\
\hline Age, median (min, max) & $34(19,60)$ & $37(20,63)$ \\
\hline \multicolumn{3}{|l|}{ Job category $n(\%)$} \\
\hline Cane harvesters & $106(100)$ & NA \\
\hline Office workers & NA & $21(33.3)$ \\
\hline Field-based jobs (supervisors and one bus driver) ${ }^{\mathrm{a}}$ & NA & $14(22.2)$ \\
\hline Plant/machine shop/storage worker & NA & $18(28.6)$ \\
\hline Other (cafeteria, electrician, occupational safety staff, guard) & NA & $10(15.9)$ \\
\hline Number of harvests worked, median (min, max) & $5(1,41)$ & $4(1,43)$ \\
\hline \multicolumn{3}{|l|}{ Years in current post (counting current year), $\mathrm{n}(\%)$} \\
\hline First year & $18(17.0)$ & $16(25.4)$ \\
\hline $2-5$ years & $46(43.4)$ & $18(28.6)$ \\
\hline$>5$ years & $42(39.6)$ & $29(46.0)$ \\
\hline \multicolumn{3}{|l|}{ Years in school, n (\%) } \\
\hline 0 years & $14(13.0)$ & $0(0)$ \\
\hline $1-6$ years & $78(73.6)$ & $7(11.1)$ \\
\hline $7-12$ years & $13(12.3)$ & $26(41.3)$ \\
\hline$>12$ years & $1(1)$ & $30(47.6)$ \\
\hline \multicolumn{3}{|l|}{ Country of birth, $n(\%)$} \\
\hline Nicaragua & $89(84.0)$ & $2(3.2)$ \\
\hline Costa Rica & $17(16.0)$ & $61(96.8)$ \\
\hline \multicolumn{3}{|l|}{ Housing during the harvest, $\mathrm{n}(\%)$} \\
\hline A labor camp & $87(82.1)$ & $0(0)$ \\
\hline In nearby house or apartment & $19(17.9)$ & $63(100)$ \\
\hline Drink alcohol, n (\%) & $48(45.2)$ & $48(76.1)$ \\
\hline Smoke, n (\%) & $26(24.5)$ & $11(17.5)$ \\
\hline
\end{tabular}

The bus driver was included in this category since his ambient heat exposure and required physical effort was similar to the supervisors.

evidence that symptoms are likely due to heat exposure. Finally, ergonomic and respiratory symptoms known to be related to cane cutting were more frequent among harvesters than non-harvesters, while symptoms not known to be related to cane cutting were not different between the two groups. This is in line with the a priori hypothesis and provides some validation of the results.

We compared harvesters and non-harvesters within the same company for validity concerns, but this decision caused notable socio-demographic differences between our comparison groups. The non-harvesters were mainly Costa Ricans with higher education levels living in their own homes. Social determinants of health are known predictors of health outcomes [WHO, 2008] and poorer social conditions of harvesters may have played a role in increased symptom reporting. To evaluate the effect of this potential bias, we compared the frequency of symptom reporting between the Nicaraguan harvesters who lived in the labor camps away from their families during the harvest season $(n=87)$ with the Costa Rican harvesters from the area $(n=19)$. However, Costa Rican harvesters reported slightly more symptoms, suggesting such bias did not occur. Additionally, the low reporting of symptoms unrelated to heat or cane harvesting gives confidence that harvesters were not systematically reporting more symptoms than non-harvesters.

Not all harvesters from subcontractor 2 and not all potential non-harvesters were recruited, because the research team had to adapt to the company's harvest dynamics. The participants in this study were selected due to their presence while researchers were in the field, but it is unlikely that they are different from the non-recruited workers. However, the pilot study indicated that harvesters who experience severe heat exhaustion or fainting tend to stay home from work the following day and not including them could have underestimated the frequency of heat-related symptoms. Also, the physical demand of the job combined with migration will likely lead to a healthy worker effect, further attenuating the findings. This study relied on self-reported symptoms rather than diagnosed conditions. This is limiting, but these symptoms are likely to be reported with similar error among harvesters and non-harvesters, giving rise to a non-differential misclassification attenuating the differences between the groups.

Although we did not use a validated questionnaire, our questionnaire was tested in the pilot phase of the study which 
TABLE II. Frequency of Symptom Reporting by Sugarcane Harvesters and Sugarcane Non-Harvesters

\begin{tabular}{|c|c|c|c|c|c|c|c|c|c|c|}
\hline & \multicolumn{4}{|c|}{ Ever } & & \multicolumn{4}{|c|}{ At least once per week } & \multirow[b]{3}{*}{$\boldsymbol{P}$-value } \\
\hline & \multicolumn{2}{|c|}{ Harvesters $(n=106)$} & \multicolumn{2}{|c|}{ Non-harvesters $(n=63)$} & & \multicolumn{2}{|c|}{ Harvesters $(n=106)$} & \multicolumn{2}{|c|}{ Non-harvesters $(n=63)$} & \\
\hline & $\mathbf{n}$ & $\%$ & $\mathbf{n}$ & $\%$ & & $\mathbf{n}$ & $\%$ & $\mathbf{n}$ & $\%$ & \\
\hline \multicolumn{11}{|l|}{ Heat exhaustion symptoms } \\
\hline Headache & 75 & 70.8 & 32 & 50.8 & 0.006 & 54 & 50.9 & 16 & 25.4 & 0.001 \\
\hline Tachycardia & 49 & 46.2 & 10 & 15.9 & $<0.001$ & 37 & 34.9 & 3 & 4.8 & $<0.001$ \\
\hline Muscle cramps arms/legs & 41 & 38.7 & 15 & 23.8 & 0.055 & 26 & 24.5 & 7 & 11.1 & 0.037 \\
\hline Fever & 30 & 28.3 & 9 & 14.3 & 0.037 & 19 & 17.9 & 2 & 3.2 & 0.005 \\
\hline Nausea & 27 & 25.5 & 5 & 7.9 & 0.005 & 18 & 17.0 & 0 & 0.0 & $<0.001$ \\
\hline Difficulty breathing & 21 & 19.8 & 7 & 11.1 & 0.363 & 14 & 13.2 & $\mathbf{0}$ & 0.0 & 0.003 \\
\hline Dizziness & 26 & 24.5 & 12 & 19.0 & 0.450 & 12 & 11.3 & 1 & 1.6 & 0.033 \\
\hline Swelling hands/feet & 16 & 15.1 & 5 & 7.9 & 0.173 & 8 & 7.5 & $\mathbf{0}$ & 0.0 & 0.026 \\
\hline Vomiting & 13 & 12.3 & 5 & 7.9 & 0.396 & 4 & 3.8 & 0 & 0.0 & 0.298 \\
\hline Fainting & 3 & 2.8 & 0 & 0 & 0.294 & & & & & \\
\hline \multicolumn{11}{|l|}{ Dehydration symptoms } \\
\hline Dry mouth & 39 & 36.8 & 22 & 34.9 & 0.970 & 34 & 32.1 & 14 & 22.2 & 0.189 \\
\hline Dysuria & 38 & 35.8 & 8 & 12.7 & 0.001 & 30 & 28.3 & 2 & 3.2 & $<0.001$ \\
\hline \multicolumn{11}{|l|}{ Non-heat related symptoms } \\
\hline \multicolumn{11}{|l|}{ Related to cane cutting } \\
\hline Pain in lower part of back & 77 & 72.6 & 35 & 55.6 & 0.038 & 67 & 63.2 & 23 & 36.5 & 0.001 \\
\hline Pain in upper part of back & 73 & 68.9 & 37 & 58.7 & 0.142 & 59 & 55.7 & 21 & 33.3 & 0.003 \\
\hline Sneezing & 73 & 68.9 & 23 & 36.5 & $<0.001$ & 58 & 54.7 & 15 & 23.8 & $<0.001$ \\
\hline Rhinorrhea & 37 & 34.9 & 8 & 12.7 & 0.001 & 27 & 25.5 & 3 & 4.8 & 0.001 \\
\hline \multicolumn{11}{|l|}{ Not related to cane cutting } \\
\hline Stomachache & 22 & 20.8 & 14 & 22.2 & 0.848 & 12 & 11.3 & 5 & 7.9 & 0.499 \\
\hline Diarrhea & 4 & 3.8 & 9 & 14.3 & 0.018 & 3 & 2.8 & 0 & 0.0 & 0.294 \\
\hline Difficulty buttoning shirt & 3 & 2.8 & 0 & 0.0 & 0.298 & 3 & 2.8 & 0 & 0.0 & 0.294 \\
\hline Nosebleed & 8 & 7.5 & $\mathbf{0}$ & 0.0 & 0.026 & 2 & 1.9 & 0 & 0.0 & 0.530 \\
\hline Earache & 3 & 2.8 & 1 & 1.6 & 1.000 & 1 & 0.9 & 0 & 0.0 & 1.000 \\
\hline
\end{tabular}

Bold signifies $P<0.05$.

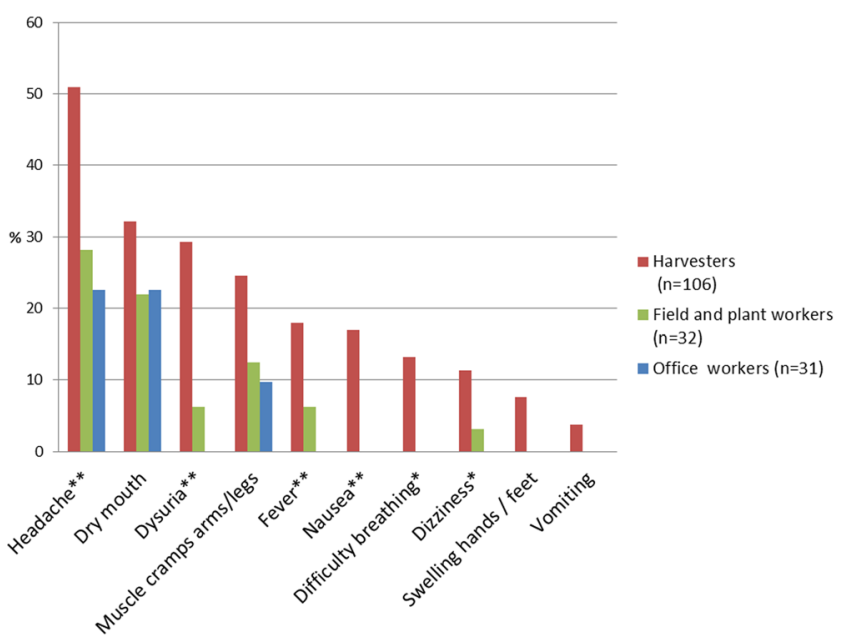

FIGURE1. Percent of participants in each job category reporting heat and dehydration symptoms at least once a week. ${ }^{*}$ Gamma statistic $P \leq 0.01,{ }^{* *} P<0.001$. allowed language adjustment and the inclusion of dehydration symptoms known to be an issue for this population: dry mouth and dysuria. Dry mouth was reported with similar frequency across all job groups, possibly due to the overall hot climate, but dysuria was significantly more frequent among harvesters in accordance with findings in Nicaragua [Ramirez-Rubio et al., 2013]. In clinical medicine, dysuria is usually associated with urinary infection, an uncommon disease among males, but a study in Nicaragua demonstrated that 50 sugarcane workers with dysuria and/or leukocyte esterase in urine all had negative urine cultures [McClean et al., 2012]. Dysuria here is likely related to dehydration rather than infection. The role of hydration in symptom reporting was not fully explored in this study, and will be important for future work.

Some heat-related symptoms (fatigue, generalized weakness, ataxia, malaise, hypotension, and altered mental status) were excluded since pilot work indicated they would 
be too difficult for self-report, but these symptoms should be further explored in the future. Of particular importance is the potential to study mental health issues linked to heat exposure [Page et al., 2007; Hansen et al., 2008a; Tawatsupa et al., 2010] which has not been studied in sugarcane harvesters. In addition, the major issue of labor productivity loss due to heat at work needs further field studies in hot parts of the world [Kjellstrom et al., 2013a,b].

\section{Implications for Protection of Workers}

This study indicates a large percentage of harvesters are experiencing some degree of heat exhaustion on a continual basis throughout the harvest season. This is worrisome since heat exposure in agricultural workers is a serious risk that can be fatal even in non-tropical environments. Acute outcomes of heat exposure including syncope, heat stroke and death have been documented in agricultural populations [MMWR and CDC, 2008], but little is known about the effects of chronically experiencing heat stress [Parsons, 2014] and the corresponding symptoms reported here.

Heat exposure and heat exhaustion in sugarcane harvesters is of particular relevance for two main reasons. First, heat exposure merits special attention in light of the CKD epidemic plaguing some populations of sugarcane harvesters in Mesoamerica [Brooks et al., 2012; Wesseling et al., 2013; Correa-Rotter et al., 2014] where increasing evidence suggests chronic heat exposure and/or dehydration may play a key role in the disease [Brooks et al., 2012; Roncal Jimenez et al., 2013; Wesseling et al., 2013]. Likewise, epidemiological studies in other parts of the world have demonstrated associations between heat waves and increased rates of hospital admissions for renal disease [Hansen et al., 2008b; Green et al., 2010; Nitschke et al., 2011; Basu et al., 2012] and associations between occupational heat stress and self-reported medically diagnosed kidney disease [Tawatsupa et al., 2012] giving reason to consider the possibility of a link between heat exposure in sugarcane workers and the CKD epidemic. In addition, the fact that current conditions imply clear risks for sugarcane harvesters provokes special concern that the expected increase in daily temperature as well as the increased frequency, severity and duration of heatwaves as a result of climate change will almost certainly create an even more severe situation for workers such as sugarcane harvesters.

The sugarcane harvesters who formed part of this study are an example of a reality repeated in many parts of the world regardless of developing country status: those that suffer negative consequences of heat exposure in the workplace tend to be poor and, often, migrant workers [Rossi Rocha et al., 2007; Stallones et al., 2009; Wesseling et al., 2011; Fleischer et al., 2013; Quandt et al., 2013; García-García, 2014]. The situation demonstrated in this study applies to sugarcane harvesters throughout Central America, but also likely applies to other job sectors and other regions of the world, especially in light of a changing climate.

This study demonstrates an urgent need to improve working conditions for sugarcane harvesters. Although hot conditions will always be a reality for those in the tropics, particularly in the face of climate change expected to augment temperatures and heat waves, this occupational risk is no different from any other and must be managed adequately to protect workers. Practical solutions including hydration, shade and work-rest ratios have been successfully regulated and implemented for agricultural populations [Jackson and Rosenberg, 2010] and could be adapted to Central American sugarcane harvesting. Finally, the negative heat-related health effects seen in this population demonstrate the need to continue to address heat exposure in agricultural workplaces in other parts of the world.

\section{ACKNOWLEDGMENTS}

The authors would like to thank Katherine Méndez Jaén, Yerlin Quirós Valverde, Yolanda Gómez Campos, Dayana Ugalde Vargas, Edgardo García Chaves, Manfred Pinto Umaña and Marjorie Hartley for their dedicated fieldwork that contributed to the results in this article. The authors also wish to acknowledge the company and its employees where the study took place for their openness to the project. The Hothaps program generously provided guidance and some funding for the design of this study. The Program on Work, Health and Environment in Central America (SALTRA) provided much of the background work for this project. Funding for this project came from the Fondo Institucional de DesarrolloAcadémico/Institutional Fund for Academic Development (FIDA) from Costa Rica's Universidad Nacional.

\section{REFERENCES}

Basu R, Pearson D, Malig B, Broadwin R, Green R. 2012. The effect of high ambient temperature on emergency room visits. Epidemiology (Cambridge, Mass) 23(6):813-820. doi: 10.1097/EDE.0b013e31826b7f97

Brooks DR, Ramirez-Rubio O, Amador JJ. 2012. CKD in Central America: A hot issue. Am J Kidney Dis 59(4):481-484. doi: 10.1053/j. ajkd.2012.01.005

Correa-Rotter R, Wesseling C, Johnson RJ. 2014. CKD of unknown origin in Central America: The case for a Mesoamerican nephropathy. Am J Kidney Dis 63(3):506-520. doi: 10.1053/j.ajkd.2013.10.062.

Crowe J, Wesseling C, Solano BR, Umaña MP, Ramírez AR, Kjellstrom T, Morales D, Nilsson M. 2013. Heat exposure in sugarcane harvesters in Costa Rica. Am J Ind Med 56(10):1157-1164. doi: 10.1002/ ajim. 22204

DARA. 2012. Climate vulnerability monitor. 2nd edition. D. I. Foundation, editor. Madrid: Estudios Gráficos Europeos, S.A. p. 
360. Retrieved from http://daraint.org/climate-vulnerability-monitor/ climate-vulnerability-monitor-2012/report/

Delgado Cortez O. 2009. Heat stress assessment among workers in a Nicaraguan sugarcane farm. Global Health Action 2:1-6. doi: 10.3402/ gha.v2i0.2069

Department of the Army and Air Force. 2003. Technical bulletin: Heat stress control and heat casualty management (TB MED 507) Air Force Pamphlet 48-152 (1). Washington, DC: Department of the Army and Air Force. p. 72.

Donoghue AM, Sinclair MJ, Bates GP. 2000. Heat exhaustion in a deep underground metalliferous mine. Occup Environ Med 57(3):165-174.

FAOSTAT. 2014. FAOSTAT. 30 September 2013. Food and Agriculture Organization of the United Nations. Rome, Italy. Retrieved from http:// faostat3.fao.org/faostat-gateway/go/to/home/E.

Fleischer NL, Tiesman HM, Sumitani J, Mize T, Amarnath KK, Bayakly AR, Murphy MW. 2013. Public health impact of heat-related illness among migrant farmworkers. Am J Prev Med 44(3):199-206. doi: 10.1016/j.amepre.2012.10.020

García-García G. 2014. Poverty: The common denominator of CKDs global threat. MEDDIC Rev 16(2):83.

Gascon M, Kromhout H, Heederik D, Eduard W, van Wendel de Joode B. 2012. Respiratory, allergy and eye problems in bagasse-exposed sugar cane workers in Costa Rica. Occup Environ Med 69(5):331-338. doi: 10.1136/oemed-2011-100029

Green RS, Basu R, Malig B, Broadwin R, Kim JJ, Ostro B. 2010. The effect of temperature on hospital admissions in nine California counties. Int J Public Health 55(2):113-121. doi: 10.1007/s00038-009-0076-0

Hancock PA, Ross JM, Szalma JL. 2007. A meta-analysis of performance response under thermal stressors. Hum Factors 49(5):851-877.

Hansen A, Bi P, Nitschke M, Ryan P, Pisaniello D, Tucker G. 2008. The effect of heat waves on mental health in a temperate Australian city. Environ Health Perspect 116(10):1369-1375. doi: 10.1289/ehp.11339

Hansen A, Bi P, Ryan P, Nitschke M, Pisaniello D, Tucker G. 2008. The effect of heat waves on hospital admissions for renal disease in a temperate city of Australia. Int J Epidemiol 37(6):1359-1365. doi: 10.1093/ije/dyn165

Jackson LL, Rosenberg HR. 2010. Preventing heat-related illness among agricultural workers. J Agromedicine 15(3):200-215. doi: 10.1080/1059924X.2010.487021

Kjellstrom T. 2009. Climate change, direct heat exposure, health and well-being in low and middle-income countries. Global Health Action 2:2-4. doi: $10.3402 /$ gha.v2i0.1958

Kjellstrom T, Crowe J. 2011. Climate change, workplace heat exposure, and occupational health and productivity in Central America. Int $\mathbf{J}$ Occup Environ Health 17(3):270-281.

Kjellstrom T, Lemke B, Otto M. 2013. Mapping occupational heat exposure and effects in South-East Asia: Ongoing time trends 1980 2011 and future estimates to 2050. Ind Health 51:56-67.

Kjellstrom T, Lemke B, Venugopal V. 2013. Occupational health and safety impacts of climate conditions. In: Climate vulnerability, Vol. 1. New York: Elsevier Publ Co. pp. 145-156 doi: 10.1016/B978-0-12384703-4.00120-9

McClean M, Amador JJ, Laws R, Kaufman JS, Weiner DE, Sánchez Rodríguez JM, Ramírez Rubio O, Brooks D. 2012. Biological sampling report: Investigating biomarkers of kidney injury and chronic kidney disease in Western Nicaragua. Boston. p. 52. Retrieved from http:// www.cao-ombudsman.org/cases/document-links/documents/Biological_Sampling_Report_April_2012.pdf.
McGeehin M, Mirabelli M. 2001. The potential impacts of climate variability and change on temperature-related morbidity and mortality in the United States. Environ Health Perspect 109(Suppl. 2): $185-189$.

MMWR and CDC. 2008. Heat-related deaths among crop workersUnited States, 1992-2006. MMWR Morb Mortal Wkly Rep 57:19922006 Retrieved from http://www.cdc.gov/mmwr/preview/mmwrhtml/ mm5724a1.htm

Nevarez J. 2013. OSHA compliance issues: OSHA heat stress fatality investigation of a Latino landscaping worker. J Occup Environ Hyg 10(6):D67-D70. doi: 10.1080/15459624.2013.784177

NIOSH. 1986. Criteria for a recommended standard: Occupational exposure to hot environments. Revised criteria 1986. Washington, DC: NIOSH. p. 140. Retrieved from http://www.cdc.gov/niosh/docs/86$113 /$

Nitschke M, Tucker GR, Hansen AL, Williams S, Zhang Y, Bi P. 2011. Impact of two recent extreme heat episodes on morbidity and mortality in Adelaide, South Australia: A case-series analysis. Environ Health 10:42. doi: $10.1186 / 1476-069 X-10-42$

Page LA, Hajat S, Kovats RS. 2007. Relationship between daily suicide counts and temperature in England and Wales. Br J Psychiatry 191:106112. doi: $10.1192 /$ bjp.bp. 106.031948

Parsons K. 2014. Human thermal environments: The effects of hot, moderate, and cold evironments on human health, comfort and performance. 3rd edition. CRC Press: London p. 635.

Pires Bitencourt D, Ruas ÁC, Maia PA. 2012. Análise da contribuição das variáveis meteorológicas no estresse térmico associada à morte de cortadores de cana-de-açúcar [Analysis of the contribution of meteorological variables to thermal stress associated with death among sugarcane cutters]. Cad Saúde Pública 28(1):65-74.

Quandt SA, Wiggins MF, Chen H, Bischoff WE, Arcury TA. 2013. Heat Index in migrant farmworker housing: Implications for rest and recovery from work-related heat stress. Am J Public Health 103(8):e24e26. doi: 10.2105/AJPH.2012.301135

Ramirez-Rubio O, Brooks DR, Amador JJ, Kaufman JS, Weiner DE, Scammell MK. 2013. Chronic kidney disease in Nicaragua: A qualitative analysis of semi-structured interviews with physicians and pharmacists. BMC Public Health 13:350. doi: 10.1186/1471-2458-13350

Ramsey JD. 1995. Task performance in heat: A review. Ergonomics 38(1):154-165. doi: 10.1080/00140139508925092.

Robins TG, Salie F, Gwagwa T. 1998. Occupational hazards: Living conditions and physical assault of sugar cane workers in KwaZuluNatal, South Africa. South African Med J [Suid-Afrikaanse Tydskrif Vir Geneeskunde] 88(9):1117-1127.

Roncal Jimenez,CA, Ishimoto T, Lanaspa MA, Rivard CJ, Nakagawa T, Ejaz AA, Cicerchi C, Inaba S, Le M, Miyazaki M, Glaser J, CorreaRotter R, González MA, Aragón A, Wesseling C, Sánchez-Lozada LG, Johnson RJ. 2013. Fructokinase activity mediates dehydration-induced renal injury. Kidney Int 86(2):294-302. doi: 10.1038/ki.2013.492

Rossi Rocha FL, Palucci Marziale MH, Cruz Robazzi ML, do C. 2007. Poverty as a predisposing factor of illness tendencies in sugar cane workers. Rev Lat Am Enfermagem 15 Spec No: 736-741.

Sahu S, Sett M, Kjellstrom T. 2013. Heat exposure, cardiovascular stress and work productivity in rice harvesters in India: Implications for a climate change future. Ind Health 51(4):424-431.

SEPSA. 2013. Boletín Estadístico Agropecuario No. 23 [argiculture and livestock statistical bulletin no. 23]. San José, Costa Rica: SEPSA. p. 208. Retrieved from http://www.infoagro.go.cr/Documents/boletin23.pdf 
Srivastava A, Kumar R, Joseph E, Kumar A. 2000. Heat exposure study in the workplace in a glass manufacturing unit in India. Ann Occup Hyg 44(6):449-453.

Stallones L, Acosta MSV, Sample P, Bigelow P, Rosales M. 2009 Perspectives on safety and health among migrant and seasonal farmworkers in the United States and México: A qualitative field study. J Rural Health 25(2):219-225. doi: 10.1111/j.17480361.2009.00221.x

Stoecklin-Marois M, Hennessy-Burt T, Mitchell D, Schenker M. 2013 Heat-related illness knowledge and practices among California hired farm workers in the MICASA Study. Ind Health 51(1):47-55.

Tawatsupa B, Lim LL-Y, Kjellstrom T, Seubsman S-A, Sleigh A, The Thai Cohort Study Team. 2012. Association between occupational heat stress and kidney disease among 37,816 workers in the Thai Cohort Study (TCS). J Epidemiol 22(3):251-260. doi: 10.2188/jea. JE20110082

Tawatsupa B, Lim LL-Y, Kjellstrom T, Seubsman S-A, Sleigh A. The Thai Cohort Study Team. 2010. The association between overall health, psychological distress, and occupational heat stress among a large national cohort of 40,913 Thai workers. Global Health Action 3(9): 110. doi: $10.3402 /$ gha.v3i0.5034

Vergüizas Valverde M, van Wendel de Joode B, Rojas Garbanzo M. 2007. Metodologías participativas: Prevención de riesgos laborales
[Participatory methodologies: Prevention of occupational risks]. Heredia. p. 36. Retrieved from http://www.saltra.una.ac.cr/index.php/ sst-vol-5

Wesseling C, Crowe J, Hogstedt C, Jakobsson K, Lucas R, Wegman DH. 2013. Resolving the enigma of the Mesoamerican nephropathy: A research workshop summary. Am J Kidney Dis 63(3):396-404. doi: 10.1053/j.ajkd.2013.08.014

Wesseling C, Crowe J, Peraza S, Aragón A, Partanen T. 2011. Trabajadores de la caña de azúcar [Sugarcane workers]. In Una mirada a las condiciones de trabajo de algunos colectivos especialmente vulnerables [A look at especially vulnerable occupational groups]. Madrid: OISS/INSHT. pp. 87-99. Retrieved from: http://www.oiss.org/ spip.php?article5840

WHO. 2008. Closing the gap in a generation: Health equity through action on the social determinants of health. Final Report of the Commission on Social Determinants of Health. Geneva: WHO. p. 248. Retrieved from http://www.who.int/social determinants/thecommission/finalreport/en/

Work performed at:Regional Institute for Studies onToxic Substances (IRET), Program on Health Work and Environment (SALTRA), Universidad Nacional, Costa Rica.

Disclosure Statement:The authors report no conflicts of interests. 